\title{
Inequidades de género en la regulación del cuidado infantil en la ley de contrato de trabajo
}

Gender inequalities in childcare regulation in the Employment Contract Act

\author{
Verónica Nuguer ${ }^{1}$ \\ Universidad Nacional de La Plata - Argentina
}

Revista Derechos en Acción ISSN 2525-1678/ e-ISSN 2525-1686

Año 5/N 17 Primavera 2020 (21 septiembre a 20 diciembre), 453-486

DOI: https://doi.org/10.24215/25251678e467

Recibido: 01/09/2020

Aprobado: 15/11/2020

Resumen: Las inequidades de género en el mundo del trabajo tienen como una de sus causas una injusta organización social del cuidado, que a la vez se relaciona directamente con desigualdades sociales y económicas. Las tareas de cuidado, como parte del trabajo reproductivo, han sido asignadas histórica, social, y culturalmente a las mujeres. Esto debe ser modificado por un modelo de corresponsabilidad social, que involucre a todos los actores sociales. Este trabajo toma como eje al cuidado durante la primera infancia, especialmente en los lugares de trabajo, desde la normativa internacional y nacional, fallos judiciales, doctrina y datos e informes estadísticos sobre el mercado laboral. Se aborda la legislación laboral al respecto, explicando a qué sujetos comprende, cuál

\footnotetext{
Abogada laboralista y asesora sindical. Especialista en Derecho Social (UNLP); egresada del Programa de Actualización en Género y Derecho (Facultad de Derecho, UBA) y del Programa de Actualización en Comunicación, Géneros y sexualidades (Facultad de Ciencias Sociales, UBA). Este artículo aborda algunos aspectos del Trabajo Final Integrador de la Especialización en Derecho Social (del Trabajo y de la Previsión) realizado por la autora (ORCID: https://orcid.org/0000-0003-1147-7675)..
} 
es su regulación en la Ley de Contrato de Trabajo y si ésta implica un modelo basado en igualdad de oportunidades. Finalmente, se analiza su inconstitucionalidad, tanto por omisión de reglamentación como por violación al principio de igualdad.

Palabras clave: inequidad de género - cuidado infantil - Ley de Contrato de Trabajo - inconstitucionalidad

Abstract: One of the causes of gender inequalities related to labor is an unjust social organization of care, which in turn is directly related to social and economic inequalities. Care tasks, as part of reproductive work, have been historically, socially, and culturally assigned to women. This must be modified by a model of social co-responsibility, which involves all social actors. This work focuses on early childhood care, especially in the workplace, from international and national regulations, court rulings, doctrine, and data and statistical reports on the labor market. The labor legislation in this regard is addressed, explaining which subjects it comprises, what is its regulation in the Employment Contract Act and if it implies a model based on equal opportunities. Finally, its unconstitutionality is analyzed, both by omission of regulation and by violation of the principle of equality.

Keywords: gender inequality - childcare - Employment Contract Act unconstitutionality

\section{Introducción}

Si bien en los últimos años ha aumentado a nivel mundial la participación de las mujeres en el mercado de trabajo, éstas no lo hacen en las mismas condiciones que los varones, sino en un contexto de más dificultoso acceso, y de menores desarrollo y permanencia en el empleo.

Las mujeres sufren un mayor desempleo; en Argentina en 2019 era del 10,8\% frente al 8,9\% de los varones ${ }^{2}$, y una mayor precarización en sus condiciones laborales ${ }^{3}$.

2 Instituto Nacional de Estadística y Censos (INDEC) (2020) "Mercado de trabajo. Tasas e indicadores socioeconómicos (EPH) Primer trimestre de 2020" Trabajo e ingresos Vol. 4, 
Han aumentado las familias con jefatura de hogar femenina, en un contexto de "feminización de la pobreza" las mujeres con hijos/as quienes se encuentran en mayor desventaja.

Las desigualdades entre géneros en el mercado de trabajo ${ }^{5}$, también denominadas "brechas" son resultado, entre otros fenómenos, de la segregación horizontal, la segregación vertical, la brecha salarial y las bajas participación y representación sindical ${ }^{6}$.

Habitualmente se paga menos a las mujeres que a los varones por el mismo trabajo o uno distinto, pero de igual valor, lo que se denomina "brecha salarial" y cuanto más "femenina" es la ocupación, menor es el salario. Otro aspecto que influye es el tiempo de trabajo remunerado; las mujeres, por las responsabilidades familiares que ejercen, especialmente en sectores de bajos recursos donde el trabajo está más flexibilizado y menos protegido, trabajan menos horas, lo que repercute en su

$n^{0} 3$, Buenos Aires, disponible en https://www.indec.gob.ar/uploads/informesdeprensa/ mercado_trabajo_eph_1trim20AF03C1677F.pdf . Datos para el tercer trimestre de 2019

3 El porcentaje de mujeres con empleo no registrado entre la población de 16 años y más es del 34,9\% frente al 31,5\% de los varones, según elaboración de DGlyEL SSPEyEL publicada en el Documento "Las Mujeres en el Mundo del Trabajo" Septiembre 2017, Dirección de Equidad de Género e Igualdad de Oportunidades en el Trabajo, Ministerio de Trabajo, Empleo y Seguridad Social de Argentina

4 Según el Informe "Pobreza y Desigualdad por Ingresos en la Argentina Urbana 20102016" elaborado por el Observatorio de la Deuda Social Argentina de la Universidad Católica Argentina (UCA), el 23,1\% de hogares de nuestro país tienen ingresos bajo la línea de pobreza y con jefatura de hogar a cargo de una mujer, mientras que en el caso de jefatura a cargo de un varón, ascienden al 21,6\%, diferencia que se acrecienta en situación de indigencia

5 Si bien en este trabajo nos referimos en general a varones y mujeres, destacamos que otras identidades de género y el apartamiendo de la heteronormatividad son también motivos de las discriminaciones mencionadas

6 Coordinación de Equidad de Género e Igualdad de Oportunidades en el Trabajo, Ministerio de Trabajo, Empleo y Seguridad Social de Argentina (2014) "Indicadores más relevantes de la inserción de mujeres y los varones en el mercado de trabajo", disponible en http:// www.trabajo.gov.ar/downloads/cegiot/140703_brochure.pdf 
ingreso. En Argentina la brecha salarial entre varones y mujeres era de $23,5 \%$ en $2016^{7}$.

Las diversas inequidades de género del mundo laboral se relacionan directamente con las desigualdades sociales y económicas. Otro de los factores que incide es la tradicional división de roles en el marco de una cultura androcéntrica, patriarcal y capitalista, que asigna el trabajo productivo a los varones y el reproductivo a las mujeres, que no es remunerado generalmente. La división sexual del trabajo se vincula asimismo con estereotipos de género que se reproducen socialmente y que contribuyen a sostener estas inequidades.

Estas desigualdades tienen como una de sus causas una injusta organización social del cuidado, que incide directamente en la vida de las personas. Las tareas de cuidado, parte del trabajo reproductivo, han sido asignadas histórica, social, y culturalmente a las mujeres.

Las Encuestas de Uso del Tiempo ${ }^{8}$ corroboran esta situación: ellas dedican en promedio 3 horas diarias más a estas actividades que los varones. El desempleo en mujeres jóvenes de hasta 29 años es del $22,6 \%$, mientras que en el caso de los varones es del $17,9 \%$, representando el sector de mayor desocupación de toda la población?. Sin embargo, una parte importante de ellas realiza tareas de cuidado no remuneradas esenciales para el sostenimiento y la reproducción de la sociedad (De León, 2017, pág. 17) ${ }^{10}$.

\footnotetext{
7 Datos promedio de asalariados y asalariadas del sector privado registrados para el $4^{\circ}$ trimestre de 2016 según elaboración de SSPEyEL publicada en el Documento "Las Mujeres en el Mundo del Trabajo - Septiembre 2017", Dirección de Equidad de Género e Igualdad de Oportunidades en el Trabajo, Ministerio de Trabajo, Empleo y Seguridad Social de Argentina

8 En 2014 el Indec publicó los resultados de la primera "Encuesta sobre trabajo no remunerado y uso del tiempo", luego en 2016 la Dirección General de Estadísticas y Censos del Ministerio de Hacienda de la Ciudad de Buenos Aires presentó los resultados del informe "Uso del tiempo Ciudad de Buenos Aires 2016"

9 Instituto Nacional de Estadística y Censos (INDEC) (2020) “Mercado de trabajo. Tasas e indicadores socioeconómicos (EPH) Primer trimestre de 2020" Trabajo e ingresos Vol. 4, n 3 , Buenos Aires, disponible en https://www.indec.gob.ar/uploads/informesdeprensa/mercado_trabajo_eph_1trim20AF03C1677F.pdf. Datos para el tercer trimestre de 2019
} 
La sociedad se aprovecha de los "cuidados", que constituyen una actividad de reproducción social no asalariada necesaria para el sistema. Estas actividades, según Fraser (2015):

sirven para producir nuevas generaciones de trabajadores y reponer las existentes, así como para mantener los vínculos sociales y las mentalidades compartidas. La reproducción social es una condición de fondo indispensable para la posibilidad de la producción económica en una sociedad capitalista. (...) las sociedades capitalistas han separado el trabajo de reproducción social del trabajo de reproducción económica. Asociando el primero con las mujeres (...) oscureciendo su importancia y su valor. (pág.114 y 115) ${ }^{11}$.

Explican Rodríguez Enríquez y Marzonetto (2015) que la manera en que se organiza socialmente el cuidado "tiene implicancias determinantes para los niveles de desigualdad social, siendo afectada y afectando la estratificación social y la situación de (in)equidad de género" (pág. 103) ${ }^{12}$. Nuestra organización social del cuidado, según estas mismas autoras,

es injusta y se convierte en sí misma en un vector de reproducción de la desigualdad socio-económica y de género (...) se sugiere la necesidad de promover políticas públicas que redistribuyan las responsabilidades de cuidado, consiguiendo de esa manera desmantelar los obstáculos que su injusta distribución produce a la participación económica (especialmente de las mujeres) y con ello alcanzar mayor justicia distributiva (pág. 104) ${ }^{13}$.

10 De León, Gimena (2017) Jóvenes que cuidan: impactos en su inclusión social, CIPPEC, Buenos Aires

11 Fraser, Nancy (2015) "Las contradicciones del capital y los cuidados" en New Left Review 100 Segunda Época septiembre - octubre 2016, Traficantes de sueños, Madrid

12 Rodríguez Enríquez, Corina y Marzonetto, Gabriela (2015) “Organización social del cuidado y desigualdad: el déficit de políticas públicas de cuidado en Argentina" en Revista Perspectivas de Políticas Públicas Año 4 No 8 (Enero - Junio 2015), Ediciones de la Universidad Nacional de Lanús, Remedios de Escalada

13 ĺbid 
Alcanzar la justicia social exige tanto redistribución como reconocimiento, ya que como bien señala Fraser (2009):

el género sirve de principio organizador básico de la estructura económica de la sociedad capitalista. Por una parte, estructura la división fundamental entre trabajo retribuido "productivo" y trabajo no retribuido, "reproductivo" y doméstico, asignando a las mujeres la responsabilidad primaria de este último. Por otra parte, el género estructura también la división, dentro del trabajo pagado, entre las ocupaciones (...) El resultado es una estructura económica que genera formas de injusticia distributiva específicas de género, incluyendo la explotación basada en el género, la marginación económica y la privación. (...) Sin embargo, el género no es sólo una división semejante a la de las clases sociales, sino una diferenciación de estatus también (pág. 92) $)^{14}$.

\section{El cuidado infantil y el trabajo de las mujeres}

Siguiendo a Rodríguez Enríquez y Pautassi (2014) el cuidado abarca

las actividades indispensables para satisfacer las necesidades básicas de la existencia y reproducción de las personas, brindándoles los elementos físicos y simbólicos que les permiten vivir en sociedad (...) La organización social del cuidado (OSC) se refiere a la manera en que interrelacionadamente las familias, el Estado, el mercado y las organizaciones comunitarias, producen y distribuyen cuidado (pág. 11) ${ }^{15}$.

\footnotetext{
14 Fraser, Nancy (2009) "La justicia social en la era de la política de identidad: redistribución, reconocimiento y participación" en Revista de Trabajo, Volumen: 2009-6, Ministerio de Trabajo y Seguridad Social, Buenos Aires

15 Rodríguez Enríquez, Corina y Pautassi, Laura (2014) La organización social del cuidado de niñas y niños. Elementos para la construcción de una agenda de cuidados en Argentina, ELA - CIEPP - ADC, Buenos Aires
} 
Enfrentamos una "crisis de los cuidados", debido a varios factores, entre ellos, el envejecimiento demográfico, aumento de la esperanza de vida de personas con enfermedades crónicas y discapacidades, cambios en la estructura y dinámica familiar que limitan la disponibilidad de cuidadores, por la creciente incorporación de mujeres en el mercado laboral y jefatura femenina del hogar.

Sin embargo, señala Lupica (2014)

los hombres no se han incorporado a tales tareas en el grado que la nueva realidad social lo amerita, Ellos colaboran pero no asumen la misma responsabilidad que las mujeres (...) Adicionalmente, tampoco se ha producido aumento significativo en la provisión de servicios públicos de cuidados ni se ha logrado reorganizar la institucionalidad que norma la vida social (pág. 14) ${ }^{16}$.

El cuidado infantil implica, según De León (2017), aquellas actividades y servicios de cuidado destinados a la atención de las necesidades y particularidades de los niños y niñas (...) es fundamental ya que la infancia es el periodo de las trayectorias vitales, cuando los individuos desarrollan sus capacidades psíquicas, mentales, emocionales y de aprendizaje que los influirán por el resto de sus vidas (pág. 16) ${ }^{17}$.

Puede desarrollarse de diversas maneras; en el ámbito doméstico mediante trabajo no remunerado, generalmente llevado a cabo por madres u otras mujeres del grupo familiar; o mediante servicios remunerados, en su mayoría empleadas de casas particulares. Fuera del ámbito doméstico, se presta en establecimientos privados, en lugares de trabajo, en espacios estatales o comunitarios, donde también es generalmente

16 Lupica, Carina (2014) Recibir y brindar cuidados en condiciones de equidad: desafíos de la protección social y las políticas de empleo en Argentina, Oficina de País de la Oit para Argentina, Buenos Aires

17 De León, Gimena, op. cit. 
realizado por mujeres. Resulta esencial la duración de la jornada del establecimiento, ya que en supuestos de jornada simple, como son mayoritariamente, no resultan eficaces como mecanismos de solución de la tensión entre vida familiar y laboral.

No existen datos oficiales en Argentina sobre oferta educativa de nivel inicial ni sobre su concurrencia; estimándose que para niñas/os de 3 años alcanza apenas el 40\%, mientras para la franja de 0 a 2 años es del 4\% (Rodríguez Enríquez y Marzonetto, 2015, pág. 117) ${ }^{18}$. Entre quienes concurren y tienen hasta dos años, más del $60 \%$ asiste a establecimientos privados (Lupica, 2014, pág. 28) ${ }^{19}$.

El aumento en la participación de las mujeres en el empleo en los últimos años se produjo con más énfasis entre las madres y agrega De León (2017) que

la imposibilidad de abandonar las tareas del hogar y de cuidado, sumado a la inexistencia de políticas conciliatorias efectivas las lleva a insertarse en trabajos más precarios e informales (para poder conciliar ambas tareas al trabajar menos horas o con esquemas más flexibles) que no gozan de protección social y resultan en menores salarios (...) mientras las madres en condiciones socioeconómicas favorables tienden a participar en el mercado laboral de manera creciente y constante, las madres pobres e indigentes ingresan masivamente en épocas de crisis y se retiran en momentos de bonanza (pág. 22) ${ }^{20}$.

El cuidado infantil en Argentina presenta altos niveles de familiarización, privatización y feminización, que debemos revertir.

Desarrollar políticas públicas referidas al cuidado infantil, entre ellas la legislación laboral, resulta fundamental ya que

\footnotetext{
18 Rodríguez Enríquez, Corina y Marzonetto, Gabriela, op. cit.

19 Lupica, Carina, op. cit.

20 De León, Gimena, op. cit.
} 
promueven la igualdad de géneros, los derechos y desarrollo de la niñez y disminuyen la pobreza.

Reconocer el cuidado como un derecho genera obligaciones y según Rodríguez Enríquez y Pautassi (2014) "es el Estado el principal obligado a garantizar el ejercicio del derecho al cuidado libre de discriminación y bajo estándares de cantidad y calidad necesarios y suficientes, pero a la vez, debe obligar a otros sujetos a prestarlo" (pág. 173) ${ }^{21}$.

Estas políticas, que tradicionalmente tienen un sesgo maternalista, deben en cambio promover la "corresponsabilidad social". Señala Lupica (2014) al respecto:

La corresponsabilidad distribuye responsabilidades de cuidado, tanto de las familias al Estado (corresponsabilidad estatal) como de las mujeres a los hombres (corresponsabilidad paterna) (...) Al asignar más responsabilidades de cuidado al Estado y a los padres, estas políticas tienen la capacidad de reducir las inequidades de género en la carga asistencial. (pág. 111)22.

El cuidado infantil en el lugar de trabajo también beneficia a los empleadores. A pesar de que éstos argumentan usualmente que estas medidas, de acuerdo a ELA y UNICEF (2018)

generan mayores costos laborales y que resultan en una menor productividad (...) es a la inversa: ampliar las licencias y generar las condiciones e infraestructura para el cuidado de las hijas e hijos del personal mejora el crecimiento económico, la productividad y el rendimiento de las empresas, ya que disminuyen las tensiones en la conciliación de la vida familiar y laboral, permiten una mejor planificación, y fomentan un mayor compromiso de las trabajadoras y los trabajadores con su empleo.(pág. 66) ${ }^{23}$.

\footnotetext{
21 Rodríguez Enríquez, Corina y Pautassi, Laura, op. cit.

22 Lupica, Carina, op. cit.

23 ELA y UNICEF (2018) El Derecho al cuidado en las políticas de las empresas, Fondo de las Naciones Unidas para la Infancia, Buenos Aires
} 


\section{Normativa sobre igualdad de oportunidades y cuidado infantil}

El derecho a la igualdad se encuentra garantizado en diversos instrumentos internacionales ${ }^{24}$. Muchos de ellos mencionan al "sexo" como uno de los motivos vedados para un trato arbitrario. Puntualmente, la Convención sobre la Eliminación de Todas las Formas de Discriminación contra la Mujer (CEDAW), define en su art. 1 la discriminación contra la mujer, mientras que el Convenio 111 de la OIT, sobre Discriminación, Empleo y Ocupación, especifica la discriminación en ese ámbito.

Expresa Pautassi (2007), que "El "derecho al cuidado (...) integra el conjunto de los derechos universales de derechos humanos consagrados en los diversos instrumentos internacionales, a pesar de no estar explícitamente nominado como tal" (pág. 29) 25 .

Entre la normativa internacional referida al cuidado ratificada por Argentina, se encuentran la CEDAW; el Pacto Internacional de Derechos Económicos, Sociales y Culturales; el Protocolo de San Salvador; la Convención Internacional sobre los Derechos del Niño; el Consenso de Quito; el Consenso de Brasilia; y los Convenios de la OIT 100 (Igualdad de remuneración), 156 (Trabajadores con responsabilidades familiares) y 189 (Trabajo decente para las trabajadoras y los trabajadores domésticos). Destacamos los artículos 11 de la CEDAW, 3 y 5 del Convenio 156 de la OIT y 18 de la CIDN.

De las disposiciones citadas surgen, entre otras, la obligación del Estado en la instalación y prestación de servicios para el cuidado infantil y la corresponsabilidad social en las tareas

24 Entre ellos la Declaración Americana de los Derechos y Deberes del Hombre (art. 2), la Declaración Universal de Derechos Humanos (art. 2.1.), la Convención Americana de Derechos Humanos (art. 1.1), el Pacto Internacional de Derechos Económicos, Sociales y Culturales (art. 2.2)

25 Pautassi, Laura (2007) El cuidado como cuestión social desde un enfoque de derechos. Serie Mujer y Desarrollo Nº7 CEPAL, Santiago de Chile 
de cuidado, es decir entre miembros de la familia, y también entre éstas, Estado y sociedad.

Asimismo, se reconocen los derechos a no discriminación de las mujeres en el empleo y a la igualdad de oportunidades entre trabajadores y trabajadoras.

Estas normas internacionales, que tienen jerarquía constitucional o en su caso supralegal, conforme el art. 75 inc. 22 de la Constitución, reconocen la responsabilidad del Estado en la implementación de acciones para el cuidado de la niñez para promover la igualdad de género.

Dentro del texto de la Constitución Nacional Argentina, el derecho a la igualdad se encuentra garantizado en el artículo 16.

Entre las atribuciones del Congreso, el art. 75 inc. 19 prevé la sanción de leyes que aseguren la igualdad de oportunidades sin discriminación alguna, teniendo en cuenta el desarrollo humano y el progreso económico con justicia social.

El artículo 14 bis asegura la protección del trabajo, condiciones dignas y equitativas de labor; igual remuneración por igual tarea, y la obligación del Estado de otorgar los beneficios de la seguridad social y la protección integral de la familia.

Asimismo, el artículo 75 inc. 23 establece que la legislación debe promover la igualdad de oportunidades y trato, mencionando expresamente a mujeres y la niñez como destinatarios de estas políticas.

Entre la normativa nacional, la Ley 23592 dispone en su art. 1 la nulidad de los actos discriminatorios y el deber de reparación.

El art. 17 de la Ley de Contrato de Trabajo Argentina prohibe cualquier discriminación entre quienes trabajan, mencionando sexo como uno de sus motivos.

Destacamos la Ley 26485 de Protección integral para prevenir, sancionar y erradicar la violencia contra las mujeres en los ámbitos en que desarrollen sus relaciones interpersonales, que tipifica como una de las modalidades de violencia a la laboral. 
Por su parte, el Código Civil y Comercial dispone como principio el "cuidado compartido del hijo" (arts. 651 y 658) y el valor económico de las tareas de "cuidado personal del hijo" (art. 660).

En cuanto al cuidado infantil, se han sancionado leyes que lo regulan en forma directa. Entre ellas, la Ley 26021 de Protección Integral de los Derechos de Niños, Niñas y Adolescentes; la Ley 26233 de Centros de Desarrollo Infantil y la Ley 26206 de Educación Nacional.

Estas disposiciones se encuentran en consonancia con la normativa internacional y constitucional mencionada.

Asimismo, el tema ha sido abordado desde la legislación laboral, lo que analizaremos a continuación.

\section{El cuidado infantil en la legislación laboral argentina}

En una primera etapa, la legislación laboral sólo consideraba a la mujer en su condición de madre, siendo la figura de la persona asalariada la del varón, bajo el supuesto de pleno empleo masculino, en la cual, refieren Pautassi, Faur y Gherardi (2004) "las mujeres quedaron en una posición desventajosa, logrando la inclusión de determinadas normas protectoras, pero sin que se promoviera el principio de igualdad" (pág. 34) ${ }^{26}$.

En el Siglo XX las políticas públicas reforzaron la "familiarización y feminización" del cuidado, y se encontraron, para Cutuli y Aspiazu (2012) "centradas en la figura de la madre biológica y que alentaban la exclusión de las mujeres del mercado de trabajo, en particular en el período de crianza de los hijos" 27 .

\footnotetext{
26 Pautassi, Laura; Faur, Eleonor y Gherardi, Natalia (2004) Legislación laboral en seis países latinoamericanos. Límites y omisiones para una mayor equidad, Serie Mujer y Desarrollo Nº56, CEPAL, Santiago de Chile

27 Cutuli, Romina y Aspiazu, Eliana (2012) “Conciliación entre trabajo y cuidado infantil. Discriminaciones y exclusiones en el caso argentino", Grupo de Estudios del Trabajo, Facultad de Ciencias Económicas y Sociales Universidad Nacional de Mar del Plata - CONICET, Mar del Plata, disponible en http://nulan.mdp.edu.ar/1981/1/1981.pdf
} 
Así, el ideal maternalista y la "maternalización de las mujeres" se constituyeron mediante políticas públicas en el paradigma de instituciones, prácticas y representaciones sociales durante largo tiempo (Faur, 2014, pág. 16) ${ }^{28}$.

A la par, se fueron incrementando la participación de las mujeres en el mercado de trabajo y los movimientos de mujeres que reivindicaron sus derechos.

La normativa internacional fue evolucionando, y en este sentido, debemos resaltar como punto de inflexión la aprobación de la CEDAW ya que a partir de ese momento comenzó a incorporarse el principio de equidad de género en el mundo del trabajo (Pautassi, Faur y Gherardi, 2004, pág. 34) ${ }^{29}$.

En la reforma constitucional de 1994, se incorporaron al artículo 75 los incisos 19, 22 y 23, que hemos mencionado.

Sin embargo, en los años siguientes, pese a la existencia y ratificación de mecanismos y disposiciones para garantizar la equidad de género formal, la flexibilización laboral, el aumento del trabajo no registrado y la precarización, generaron mayores desventajas a las trabajadoras.

La Ley 20744 de Contrato de Trabajo, sancionada en 1974, dispone en la parte final del artículo 179 (originalmente art. 195): "En los establecimientos donde preste servicios el número mínimo de trabajadoras que determine la reglamentación, el empleador deberá habilitar salas maternales y guarderías para niños hasta la edad y en las condiciones que oportunamente se establezcan" ${ }^{\prime 30}$.

Esta disposición derogó la Ley 11317 de 1924, que regulaba el "Trabajo de las mujeres y los niños", cuyo artículo 15 consignaba: "En los establecimientos que ocupen el número mínimo

\footnotetext{
28 Faur, Eleonor (2014) El cuidado infantil en el siglo XXI: Mujeres malabaristas en una sociedad desigual, Siglo XXI Editores, Buenos Aires

29 Pautassi, Laura; Faur, Eleonor y Gherardi, Natalia, op. cit.

30 Se encuentra dentro del Título VII “Trabajo de mujeres”, Capítulo II "De la protección de la maternidad
} 
de mujeres que determine la reglamentación, deberán habilitarse salas maternales adecuadas para los niños menores de 2 años, donde éstos quedarán en custodia durante el tiempo de ocupación de las madres." ${ }^{31}$. Su reglamentación, de 1925, establecía que la obligación regía "en todo establecimiento donde se ocupen 50 (cincuenta) mujeres o más, mayores de 18 años"32.

Previamente, antes de la Ley 11317, rigió la Ley 5291 sancionada en 1907 , la primera norma referida al "Trabajo de mujeres y niños"33. En su artículo 9, inciso $8^{\circ}$, disponía que "En los establecimientos donde trabajen mujeres, se permitirá que las madres puedan amamantar a sus hijos durante quince minutos cada dos horas, sin computar este tiempo en el destinado al descanso". Es decir que sin limitación alguna respecto del número, se determinaba la obligación del empleador de contar con ese espacio.

Volviendo a la Ley de Contrato de Trabajo, el mencionado art. 179 se titula "Descansos diarios por lactancia", refiriéndose a ello la primera parte de la norma. Sin embargo, su parte final, alusiva a espacios de cuidado infantil, si bien guarda relación, excede a situaciones que serían estrictamente de lactancia.

Históricamente la existencia de este recinto para el cuidado se vinculaba con el regreso de la trabajadora a prestar tareas finalizada la licencia por maternidad y la continuidad de la lactancia materna. Sin embargo, actualmente existen otras situaciones, necesidades y posibilidades que lo tornan independiente de ella. Consideramos que deberían separarse ambas disposiciones, que pueden referirse a distintos sujetos. Asimismo, la primera parte de la norma podría ampliarse a más sujetos y referirse a alimentación en general y no solamente a lactancia y a amamantamiento.

31 Ley 11317 (1924) disponible en https://www.argentina.gob.ar/normativa/nacional/ley$11317-194070 /$ texto

32 Decreto 2699, artículo 3 (1925) disponible en https://www.argentina.gob.ar/normativa/ nacional/decreto-2699-1925-194075/texto

33 Ley 5291, disponible en http://www.trabajo.gob.ar/downloads/biblioteca/bdnt/1908_4.pdf 
Por otra parte, no acordamos con la denominación de dichas salas como "maternales", ya que resulta discriminatoria al asociar desde el lenguaje el cuidado a una tarea propia de madres, cuando a fin de comprender diversas situaciones familiares, podrían ser llamadas "salas cuna".

Existe además un debate sobre el uso de la palabra "guardería", que parece remitir a la guarda de objetos, cuando la legislación de la materia se refiere a desarrollo y educación infantil. Sin perjuicio de la definición de la Real Academia Española"34, resulta más acertada denominarlas salas cuna o centros, espacios, salas o lugares de cuidado infantil.

A diferencia de la ley anterior, el actual artículo 179 no dispone edad máxima de niños y niñas, sujetándola a la reglamentación. Tampoco fija horario o límite temporal en el cual debe funcionar el lugar de cuidado, mientras que la ley 11317 expresaba que era "durante el tiempo de ocupación de las madres". Asimismo, no establece que sea una prerrogativa que sólo pueden utilizar las trabajadoras, por lo que los trabajadores también se encuentran comprendidos en este derecho.

Resulta claro y coincidente entre ambas normas que el lugar de cuidado infantil debe funcionar dentro del establecimiento de trabajo, por lo que cualquier modificación de ello que se pretenda mediante la reglamentación no sería constitucionalmente válida. En ese sentido, del texto legal tampoco surge que se trate de una obligación que puede ser compensada en dinero.

Sin embargo, este artículo no prevé qué ocurre si el número de trabajadoras no alcanzara el mínimo que fije la reglamentación.

Por otra parte, debe considerarse que el artículo habla de trabajadoras que presten servicios en el establecimiento, lo que implica tener en consideración el concepto de "establecimiento"

34 Define a guardería infantil como "Lugar donde se cuida y atiende a los niños de corta edad", Real Academia Española (2020) Diccionario de la Lengua Española,disponible en https://dle.rae.es/guarder\%C3\%ADa 
(art. 6 de la LCT) así como lo dispuesto en los arts. 23, 29 y 30 de la ley 20744.

El artículo 179 de la ley 20744, transcurridos más de cuarenta años de su sanción, no ha sido reglamentado. Esto implicó que tanto la la doctrina ${ }^{35}$ como la jurisprudencia de la Cámara Nacional de Apelaciones del Trabajo entendieran que no podía exigirse su cumplimiento por falta del dictado de reglamentación ${ }^{36}$, y en consecuencia no se hiciera efectiva la obligación.

Algunos Convenios Colectivos de Trabajo $^{37}$ establecen el pago de una suma no remunerativa como beneficio social que compensa por un determinado monto máximo el costo del servicio de cuidado infantil hasta cierta edad.

También hay empresas que abonan sumas no remunerativas por este concepto, y unas pocas han creado espacios de cuidado infantil en sus establecimientos.

Existen numerosos planteos judiciales sobre el carácter que debe asignársele al pago por parte del empleador de "gastos de guardería” y el artículo 103 bis inciso F de la LCT, que dispone que éste puede brindar ciertas prestaciones cuya naturaleza es de seguridad social, y se consideran no remunerativas.

Destacamos que el reintegro de gastos que prevé el art. 103 bis inciso F se aplica a otro supuesto y que no es un reemplazo del 179, sino para los casos en que las empresas no lleguen al número de trabajadoras determinado en la reglamentación. En dicha situación, las personas trabajadoras podrían pactar con su empleadora el reintegro de "gastos de guardería" como beneficio social. Una interpretación distinta implicaría transformar la

35 Fernández Humble, Juan (1979) "La obligación de habilitar salas maternales o guarderías" en Derecho del Trabajo 1979-671, La Ley, Buenos Aires

36 Cámara Nacional de Apelaciones del Trabajo, Sala II (2007) La Ley 2007-F, 511 “Magariños Carolina Fernanda c/Galeno Argentina S.A. s/dif. de salarios", Cámara Nacional de Apelaciones del Trabajo, Sala II (1982) T. y S.S. 1982-237 "Veliz c/Cayetano Gerly S.R.L.", Cámara Nacional de apelaciones del Trabajo, Sala IV (2007) DT 2008-422 “Herrera, Alcira Mabel c/S.P.M"

37 Entre ellos el CCT 103/75, el CCT 122/75 y el CCT 301/75 
obligación del art. 179 en una mera facultad para el empleador, cuando expresamente ésta dice "deberá", modificando el sentido de la norma en perjuicio de quienes trabajan.

Otro de los problemas, que será analizado posteriormente, es que tanto la norma vigente actualmente, como la anterior, sujetan la creación del lugar de cuidado al número de mujeres que se desempeñen en el establecimiento.

\section{Exclusiones de la Ley de Contrato de Trabajo}

La LCT no se aplica a todas las personas que trabajan en relación de dependencia. Se encuentran excluidas de ella las personas mencionadas en su art. 2 y quienes no tengan empleo registrado, sean autonómos/as, figuren como "monotributistas", y trabajadores y trabajadoras de la economía popular.

La normativa referida al personal de casas particulares (en su casi totalidad mujeres, ya que éstas representan el 98,7\% ${ }^{38}$, y a la vez la actividad que más las concentra, desempeñándose en la misma el $19,6 \%$ de las trabajadoras ${ }^{39}$ ), no contiene disposiciones sobre cuidado infantil.

El empleo público y quienes trabajan en el campo ${ }^{40}$ cuentan con regulaciones propias sobre la materia.

Las políticas de cuidado infantil de la legislación laboral se encuentran limitadas al empleo formal, pero ni siquiera abarcan a la totalidad de personas trabajadoras registradas. Ello

38 Según elaboración de SSPEyEL publicada en el Documento “Las Mujeres en el Mundo del Trabajo - Septiembre 2017", Dirección de Equidad de Género e Igualdad de Oportunidades en el Trabajo, Ministerio de Trabajo, Empleo y Seguridad Social de Argentina, disponible en http://trabajo.gob.ar/downloads/cegiot/Informe_CTIO_DocumentoDeTrabajo.pdf

39 Dirección de Relaciones Económicas con las Provincias -DINREP, Subsecretaría de Relaciones con Provincias, Secretaría de Hacienda, Ministerio de Economía y Finanzas Públicas (2015) “Características de la fuerza de trabajo femenina. Las diferencias respecto del hombre", disponible en http://www2.mecon.gov.ar/hacienda/dinrep/Informes/archivos/Car acteristicasdelafuerzadetrabajofemenina.pdf

40 El art. 64 de la Ley 26727 se establece la creación de "espacios de cuidado y contención" dejando sujeto a la reglamentación sus requisitos, la que aún no ha sido dictada 
genera una mayor desprotección a quienes por no tener empleo registrado ya se encuentran en una situación de vulnerabilidad, en su mayoría mujeres. Solamente el $50 \%$ de las trabajadoras se desempeña en el sector formal (Faur, 2005, p. 136) ${ }^{41}$, y de ellas estarían incluidas dentro del art. 179 de la LCT quienes se encuentren comprendidas en dicha ley y además se desempeñen en empresas del tamaño que fije la reglamentación.

Debe considerarse que el $20 \%$ de los puestos de trabajo del sector privado corresponde a establecimientos de menos de 10 dependientes, y otro $20 \%$ a establecimientos de entre 10 y 50 . A su vez, en establecimientos más pequeños los sueldos son más bajos en promedio ${ }^{42}$. De lo expuesto resulta que si se fijara un piso de cincuenta "trabajadoras" implicaría una gran restricción respecto del número de sujetos beneficiarios.

\section{Análisis de la constitucionalidad del artículo 179 LCT de Argentina}

Un cuestionamiento inicial a esta disposición es que la regulación del cuidado infantil se encuentre en la Ley de Contrato de Trabajo, con las exclusiones de derecho y de hecho que se producen respecto de la misma, ya señaladas. Partimos de una norma que no lo regula para todas las personas que trabajan y lo requieran. Ello contraviene la característica de "universalidad" que implica reconocer al cuidado como un derecho, garantizado en los instrumentos internacionales citados. Sólo así puede promoverse la igualdad de oportunidades.

Sin perjuicio de lo expuesto, desarrollaremos dos cuestiones constitucionales con respecto a la última parte del art. 179

\footnotetext{
41 Faur, Eleonor (2005) "Género y conciliación Familia - Trabajo: Legislación laboral y subjetividades masculinas en América Latina" en Mora, Luis y otros (coords.) Cohesión Social, Políticas Conciliatorias y Presupuesto Público, UNFPA y GTZ, México

42 Informe del INDEC sobre Puestos de trabajo y remuneraciones de los asalariados registrados del sector privado para el Cuarto trimestre de 2016 disponible en https://www.indec. gob.ar/uploads/informesdeprensa/erl_04_17.pdf
} 
de la LCT. Por un lado, la omisión del Poder Ejecutivo Nacional en dictar la reglamentación sobre el número mínimo de trabajadoras, edad máxima de niños y niñas y demás condiciones, que ha implicado que desde su sanción hace más de cuarenta años, ésta no fuera aplicada. El otro problema es que la obligación del empleador quede sujeta al número mínimo de "trabajadoras" que preste servicios en el establecimiento.

\section{Inconstitucionalidad por omisión de reglamentación}

A principios de 2017, la Cámara Nacional Contencioso Administrativo Federal, dictó el fallo "Etcheverry" «3 , condenando al Poder Ejecutivo Nacional a que en el plazo de noventa días reglamente la última parte del art. 179 de la LCT.

El caso se encuentra a resolución de la Corte Suprema de Justicia, que a raíz de una queja del Poder Ejecutivo, solicitó ese mismo año la remisión de los autos principales.

La parte actora del juicio solicitó que se declare la inconstitucionalidad por omisión del Poder Ejecutivo en reglamentar este artículo.

En su defensa, el Ministerio de Trabajo cuestionó la vía del amparo y sostuvo que esa omisión se encuentra subsanada por la legislación vigente o los convenios colectivos que lo regulan. Pretende así que la obligación se tenga por cumplida mediante los beneficios sociales que establece el art. 103 bis de la LCT $^{44}$.

Por el contrario, destacamos que los beneficios enumerados en el art. 103 bis de la LCT son una mera facultad del empleador y no una obligación legal. Lo contrario implicaría privar de fuerza normativa al art. 179. Y asimismo, no puede equipararse contar con un centro de cuidado infantil en el lugar de trabajo

\footnotetext{
43 Cámara Nacional en lo Contencioso Administrativo Federal, Sala I (2017) SAIJ: FA17100001 "Etcheverry, Juan Bautista y Otros c/ Estado Nacional s/Amparo Ley 16.986"

44 Entre los "beneficios sociales", menciona en el inciso f) "Los reintegros documentados con comprobantes de gastos de guardería y/o sala maternal, que utilicen los trabajadores con hijos de hasta seis (6) años de edad cuando la empresa no contare con esas instalaciones"
} 
con un reintegro de gastos por un servicio prestado en otro establecimiento.

La sentencia de primera instancia, en consonancia con el dictamen fiscal, rechazó la acción argumentando que la parte actora no probó el perjuicio alegado.

El fiscal de Cámara, contrariamente a lo sostenido por el fiscal y el juez de primera instancia, consideró que la vía del amparo es procedente, por cuanto el tiempo transcurrido sin dictarse la reglamentación "agrava la lesión constitucional". Señaló asimismo que esta omisión es manifiestamente ilegítima desde su promulgación en 1974, y que ha importado "en la práctica, anular la operatividad del derecho legalmente consagrado, a pesar de que ese derecho protege un interés internacionalmente reconocido" ${ }^{45}$, citando el art. 18 de la Convención Internacional de los Derechos del Niño y el art. 11 de la Convención sobre la eliminación de todas las formas de discriminación contra la Mujer. Asimismo sostuvo que resulta lesivo de los derechos garantizados en las normas internacionales y de la Constitución que hemos citado anteriormente (art. 75 inc. 23 y art. 14 bis, entre otras).

El dictamen y fallo de Cámara resultan destacables en cuanto declaran la inconstitucionalidad por omisión reglamentaria. Asimismo interpretan que la articulación entre los artículos 179 y 103 bis inc f. de la LCT, debe ser de complementariedad, como ya hemos explicado, resaltándose la vigencia de la obligación de que el espacio de cuidado infantil sea "en" el lugar de trabajo. Por otra parte, si bien la norma no formula distinciones, expresamente deja asentado que puede ser utilizado tanto por trabajadoras como por trabajadores.

Con posterioridad, en septiembre de 2018, el Procurador ante la Corte Suprema emitió dictamen para este caso $^{46}$,

45 Dictamen Fiscal del Fiscal General en lo Civil y Comercial Federal y en lo Contencioso Adminsitrativo Federal (2016) "Etcheverry, Juan Bautista y Otros c/ Estado Nacional s/Amparo Ley 16.986" disponible en http://public.diariojudicial.com/documentos/000/072/736/000072736.pdf 46 Procuración General de la Nación (2018) CAF 49220/2015/1/RH1 “Etcheverry, Juan Bautista y Otros c/ Estado Nacional s/Amparo Ley 16.986" 
opinando que corresponde confirmar la sentencia de Cámara cuestionada.

Con argumentos similares a los del fiscal de Cámara, sostiene la constitucionalidad de la condena al Poder Ejecutivo Nacional a dictar la reglamentación de la parte final del art. 179 de la LCT, por cuanto la misma no resulta violatoria del "principio republicano de división de poderes" y "se encuentra dentro de las facultades jurisdiccionales.". En el mismo sentido que el dictamen anterior, sostiene que tanto el art. 103 bis inc. f) como los convenios colectivos que contemplan servicios de cuidado no suplen la obligación la omisión del Poder Ejecutivo Nacional en reglamentar la norma.

El Poder Ejecutivo se encuentra obligado a realizar la actividad de reglamentación conforme el artículo 99 inc. 2 de la Constitución y su incumplimiento constituye una inconstitucionalidad. En este caso, ha transcurrido un plazo más que razonable para que esta obligación pudiera ser ejercida.

Si bien este dictamen también se basa en la normativa internacional citada anteriormente, realiza una serie de consideraciones de suma relevancia en materia de corresponsabilidad del cuidado, tanto entre los miembros de la familia como respecto de la organización social del cuidado, concepto que ya hemos explicado y abordaremos nuevamente en el próximo apartado.

Así, expresa que la finalidad del art. 179 de la LCT es "facilitar a los trabajadores la asistencia en las tareas de cuidado a fin de alcanzar una adecuada conciliación de los deberes laborales con las responsabilidades familiares.".

El dictamen también hace referencia al "derecho a la protección de la vida familiar" y a la obligación del Estado de "generar condiciones paritarias entre los cónyuges en las tareas de cuidado y en las responsabilidades familiares, y evitar que esas tareas y responsabilidades constituyan un factor discriminatorio en perjuicio de las mujeres en diferentes ámbitos, en especial, en la esfera laboral", lo que será analizado más adelante. Y concluye expresando que la reglamentación que debe dictar el 
Poder Ejecutivo debe cumplir con el marco constitucional y convencional citado, dando algunas pautas sobre ello.

Sobre este mismo punto, el Comité de Expertos en Aplicación de Convenios y Recomendaciones de la OIT (CEACR) formuló una observación a Argentina en el año 2000 referida al Convenio sobre los trabajadores con responsabilidades familiares (C 156 OIT)

Destacamos que este Comité es un órgano de la OIT cuya función es evaluar el cumplimiento de las obligaciones contraídas por los Estados Miembros, entre ellas, de los convenios ratificados.

En su observación, el CEACR destacó la falta de aplicación del art. 179 por no haberse dictado su reglamentación, solicitando al Estado que informe si prevé reglamentarlo y que detalle "las condiciones reales de los servicios e instalaciones comunitarias de asistencia a la infancia y de asistencia familiar" ${ }^{37}$.

Esperamos que la Corte Suprema de Justicia de la Nación confirme finalmente la condena al Poder Ejecutivo Nacional y éste dicte la correspondiente reglamentación. Luego deberá analizarse si la misma cumple o no los estándares constitucionales, convencionales y legales sobre la materia que hemos mencionado a lo largo de este trabajo. Sin perjuicio de la trascendencia de la sentencia de Cámara del caso, debemos señalar que allí no se aborda otro de los cuestionamientos que presenta el art. 179 de la LCT, que es de condicionar el derecho al espacio de cuidado al número mínimo de "trabajadoras" del establecimiento. Si bien ello no fue planteado por la parte actora y por tanto no era materia de debate, destacamos que el dictamen de Segunda Instancia en su página 9, en el párrafo que anteriormente hemos transcripto, incurre en un error al consignar que debe reglamentarse el número mínimos de "trabajadores", cuando la ley dice "trabajadoras".

47 Solicitud directa (CEACR) - Adopción: 2000, Publicación: 89a reunión CIT (2001), artículo 5, disponible en https://www.ilo.org/dyn/normlex/es/f?p=1000:13100:0::N0:13100 :P13100_COMMENT_ID:2190769 
Por su parte, el dictamen del Procurador ante la Corte Suprema sí se refiere a ello, como veremos a continuación.

\section{Inconstitucionalidad por violación al principio de igualdad}

El concepto constitucional de "igualdad de oportunidades" implica una visión estructural de la desigualdad vinculado a las denominadas por la Corte de Estados Unidos "categorías sospechosas". El principio de igualdad, explica Saba ${ }^{48}$, debe entenderse como "no-sometimiento o no exclusión" de ciertos grupos que históricamente se han encontrado en esa situación como consecuencia de prácticas sistemáticas de exclusión social, económica y política, debiéndose instaurar acciones afirmativas en su favor a fin de desmantelar estas situaciones (Saba, 2008, pág. 7 y siguientes).

Conforme los supuestos de inequidad analizados, la condición de género, es decir el conjunto de trabajadoras en el mundo del trabajo puede ser entendida como una "categoría sospechosa".

La desigualdad, siguiendo a Clérico y Aldao (2011), además de dominación y sometimiento "combina problemas de redistribución y reconocimiento" (pág. 143) ${ }^{49}$, retomando así los conceptos de Fraser mencionados. Proponen estos autores "ampliar la mirada para comprender que la desigualdad no sólo deviene de una distribución injusta de los bienes económicos y sociales sino también del reconocimiento", las desigualdades son bidimensionales: "la injusticia socioeconómica, arraigada en la estructura político-económica de la sociedad respecto de la distribución de bienes" y "la injusticia cultural o simbólica,

\footnotetext{
48 Saba, Roberto P. (2008) “Igualdad, Clases y Clasificaciones: ¿Qué es lo sospechoso de las categorías sospechosas?" en Gargarella, Roberto, Teoría y Crítica del Derecho Constitucional, Tomo II, Abeledo Perrot, Buenos Aires

49 Clérico, Laura y Aldao, Martín (2011) “Nuevas miradas de la igualdad en la jurisprudencia de la Corte Interamericana de Derechos Humanos: la igualdad como redistribución y como reconocimiento", en Lecciones y Ensayos, nro. 89, Eudeba, Buenos Aires
} 
arraigada en los patrones sociales dominantes en una sociedad" (pág 146 y 147) $)^{50}$.

Las trabajadoras se ven afectadas por ambas desigualdades, y para remediarlas, según Clérico y Aldado (2011) "se requiere que las exigencias de reconocimiento cultural se integren con las pretensiones de redistribución socioeconómica"(pág. 158) ${ }^{51}$. Para ello, resulta fundamental reconocer el valor económico del trabajo no remunerado y deconstruir los estereotipos de género para asignarle el valor social que corresponde.

El cumplimiento de la obligación de los empleadores de contar con espacios de cuidado infantil en sus establecimientos permitiría a las mujeres incrementar su acceso al empleo, permanecer en el mismo, y por tanto mejorar su condición económica, a la vez que podría propender a la corresponsabilidad en estas tareas con los varones.

Considerar el género como una "categoría sospechosa" tiene como consecuencia que en caso de existir conductas y/o actos del Estado, incluida la legislación, o de particulares; que menoscaben los derechos de este conjunto, deben ser sometidas al escrutinio estricto del control de constitucionalidad y convencionalidad, a fin de corroborar si soportan un test de constitucionalidad. Este "escrutinio estricto" debe utilizar pautas interpretativas que impliquen la "no perpetuación de la inferioridad" y presunciones en su favor.

A pesar de las inequidades de género mencionadas, estas cuestiones han sido objeto de escasos precedentes jurisprudenciales, que lenta y paulatinamente comienzan a dictarse.

En el fallo "Freddo"52 la Cámara Nacional de Apelaciones en lo Civil estableció que existe una presunción de discriminación que se produce

\footnotetext{
50 ĺbid,

51 ĺbid,

52 Cámara Nacional de Apelaciones en lo Civil, Sala H (2002) SAIJ: FA02020188 "Fundación Mujeres en Igualdad y Otro c/ Freddo S.A. s/ Amparo"
} 
cuando quienes se encuentran en la situación desigual pertenecen a grupos que históricamente se encontraron en desventaja. Debe asegurarse a las mujeres no ser discriminadas en el acceso a los puestos de trabajo por su condición, así como el acceso a los puestos de mayor jerarquía, hechos que suelen ocurrir en la práctica. A la vez, también debe garantizarse que no sean despedidas por tal razón, que las condiciones de trabajo sean semejantes y, por último, que perciban la misma remuneración que un hombre que realiza una tarea similar ${ }^{53}$.

Asimismo, los jueces sostuvieron que "cualquier distinción desfavorable hacia una persona con motivo de su raza, religión, nacionalidad, sexo, condición social, aspecto físico, lengua u otras similares se presume inconstitucional".

Posteriormente, ha sido señalado en el Dictamen Fiscal ante la Corte Suprema en el caso "Sisnero" ${ }^{4}$, que el derecho a la igualdad

implica que el Estado no puede tener en su ordenamiento regulaciones discriminatorias, pero, además, que debe asumir una actitud activa para combatir las prácticas discriminatorias (...) El fundamento de la doctrina de las categorías sospechosas es revertir la situación de vulnerabilidad en la que se encuentran los miembros de ciertos grupos socialmente desaventajados como consecuencia del tratamiento hostil que históricamente han recibido y de los prejuicios o estereotipos discriminatorios a los que se los asocia aun en la actualidad. Desde este punto de vista, el género constituye una categoría sospechosa (...) las relaciones de poder entre hombres y mujeres han sido históricamente desiguales.

53 Cámara Nacional de Apelaciones en lo Civil, Sala H (2002) SAIJ: FA02020188 “Fundación Mujeres en Igualdad y Otro c/ Freddo S.A. s/ Amparo"

54 Procuración General de la Nación (2013) S.C. 8.932, L. XLVI "Sisnero, Mirtha Graciela y otros c/ Taldelva SRL y otros s/ Amparo" y Dictamen Fiscal de fecha 24/6/2013 
Destacamos que en este dictamen se hace referencia expresa al género como "categoría sospechosa" y la desigualdad histórica, que debe ser revertida.

En el mismo sentido, el dictamen de la Procuración en "Ríos Zorrilla" ${ }^{55}$, expresó que

El Estado está obligado a promover la igualdad de trato en materia de empleo y ocupación "el Convenio 111 de la OIT establece la obligación de 'formular y llevar a cabo una política nacional que promueva [...] la igualdad [...] de trato en materia de empleo y ocupación, con objeto de eliminar cualquier discriminación a este respecto' (art. 2), y de 'derogar las disposiciones legislativas y modificar las disposiciones prácticas administrativas que sean incompatibles con dicha política' (art. 3).

Aquí se explicita claramente la obligación del Estado de modificar toda aquella normativa que sea contraria a la igualdad de trato en materia de empleo y ocupación.

En base a lo expuesto, sostenemos que el art. 179 de la LCT es inconstitucional en cuanto condiciona al "número mínimo de trabajadoras que determine la reglamentación" la obligación del empleador de establecer un espacio de cuidado infantil en el establecimiento de trabajo.

Asimismo, esta disposición reproduce inequidades de género, las profundiza y no promueve un modelo de igualdad de oportunidades. La norma establece una distinción arbitraria e irrazonable entre varones y mujeres que carece de toda justificación, debiendo referirse a personas trabajadoras. En este sentido es inconstitucional por ser contraria al derecho a la igualdad, garantizado por las diversas regulaciones citadas, entre las que destacamos el art. 1 de la CEDAW ${ }^{56}$.

55 Procuración General de la Nación (2014) S.e. R. 452, L. XLVII "Ríos Zorrilla, Clara Elena c/ González, Graciela Aida y otro s/Tribunal de Trabajo Doméstico"

56 Define como discriminación contra la mujer a "toda distinción, exclusión o restricción basada en el sexo que tenga por objeto o por resultado menoscabar o anular el reconocimiento, 
Más aún si, como explicamos, consideramos que el género es una "categoría sospechosa". Ello se verifica en las numerosas y graves situaciones de inequidad reseñadas. No solo no existe justificativo alguno para la restricción establecida en la norma, sino que ésta genera un efecto contrario en cuanto a que refuerza la discriminación hacia las trabajadoras.

En este sentido, constituye una barrera de acceso al mercado de trabajo para las mujeres, ya que las empresas pueden no contratar más trabajadoras que las que la reglamentación establezca como piso a fin de no tener que crear el espacio de cuidado, prefiriendo contratar varones ya que su número no influye a este fin. Ello resulta claramente violatorio del Convenio 111 de la OIT y de lo dispuesto en el art. 75 inc. 23 de la Constitución. En este inciso se establece que la legislación debe promover la igualdad de oportunidades y trato, mencionando específicamente a las mujeres como destinatarias de dicha política.

Partiendo de la situación en la cual el desempleo femenino es mayor que el masculino, esta disposición profundiza e incrementa el desempleo de las mujeres.

Asimismo, al desestimular la contratación de mujeres, amplía la segregación horizontal, ya que en actividades donde no hay representación femenina o ésta es menor, generalmente las de mayores salarios, se continuará optando por emplear varones, lo que contribuye a ahondar la brecha salarial. Son ejemplos de esta situación los casos "Freddo" y "Sisnero" mencionados.

El Dictamen Fiscal ante la Corte Suprema de dicho caso reconoce que la existencia de

un mercado laboral sesgado por un estereotipo de género, proyecta consecuencias disvaliosas (...) el derecho a la igualdad exige que el mercado laboral cuestionado sea modificado en la dirección de la igualdad e

goce o ejercicio por la mujer, (...) sobre la base de la igualdad del hombre y la mujer, de los derechos humanos y las libertades fundamentales en las esferas política, económica, social, cultural, civil o en cualquier otra esfera" 
impone a los actores responsables por la conformación de este mercado -entre ellos, los responsables por las contrataciones- el deber correlativo de modificarlo. ${ }^{57}$.

Con posterioridad, en el Dictamen Fiscal de primera instancia en los autos "Borda, Erica" ${ }^{58}$, del año 2017, se reitera que la discriminación laboral a las mujeres encuadra en la Ley 26485 , y que éstas integran una "categoría sospechosa", en los términos que ya hemos expuesto. Se trata de un caso similar a "Sisnero", por cuanto también aquí se plantea el derecho de la actora a ser contratada como conductora de colectivos. En el dictamen en cuestión, se señala asimismo que la lucha contra contra las desigualdades requiere "la adopción de medidas proactivas capaces de eliminar barreras estructurales que impiden la igualdad entre hombres y mujeres en el mundo laboral, porque el trabajo digno es sólo aquel que respeta los derechos de la persona humana”. Debemos también tener en cuenta que uno de los efectos de la segregación horizontal es que gran parte de las trabajadoras se encuentran excluidas de la LCT.

Otro de los efectos de la regulación actual es la estimulación a que el empleo de mujeres sea sin registración o mediante maniobras de tercerización fraudulenta, a fin de evadir su cumplimiento, aumentando la precarización, lo que también contribuye a incrementar la brecha salarial.

Ya dentro del contrato de trabajo, la inexistencia del espacio de cuidado infantil puede generar que sean las mujeres quienes deban dejar sus empleos para realizar estas tareas, lo que hemos explicado al referirnos a la división sexual del trabajo, que tiene una base cultural, y porque como consecuencia de lo expuesto perciben menores salarios que los varones.

\footnotetext{
57 Procuración General de la Nación (2013) S.C. 8.932, L. XLVI “Sisnero, Mirtha Graciela y otros c/ Taldelva SRL y otros s/ Amparo" y Dictamen Fiscal de fecha 24/6/2013

58 Juzgado Nacional de Primera Instancia del Trabajo No 50, "Borda, Erica, c/ Estado Nacional, Ministerio de Trabajo, Empleo Seguridad Social de la Nación y Otros s/ Acción de Amparo", Expte. № 25.952/2014, Dictamen Fiscal de fecha 06/06/2017
} 
La norma tampoco considera que genera una restricción arbitraria atento que existe mayor informalidad en el empleo femenino, que tiene como una de sus principales causas la concentración de trabajadoras en el trabajo en casas particulares, por lo que su ampliación al número total de personas trabajadoras generaría una mayor cobertura.

Todo ello implica una violación del derecho constitucional a la igualdad de oportunidades, profundiza las inequidades de género y refuerza los estereotipos que suponen a la mujer como única o principal responsable del cuidado infantil.

La regulación resulta también contraria al principio de corresponsabilidad parental, garantizado en el art. 11 de la CEDAW y en el Convenio 156 de la OIT.

Esto implica una restricción arbitraria al derecho de los trabajadores a cuidar, y del derecho de niños y niñas a ser cuidados por quienes ejerzan el rol parental, previsto en el art. 18 de la CIDN.

La corresponsabilidad es expresamente abordada en el Dictamen Fiscal ante la Corte Suprema del caso "Puig"59, en el cual se señala que debe incentivarse la participación de los varones en tareas de cuidado, ya que "la discriminación contra los hombres que tratan de asumir una mayor parte de las responsabilidades familiares y de los quehaceres domésticos reafirma más los estereotipos y perjudica a las mujeres". Asimismo, hace referencia a que existe un mandato constitucional de generar "condiciones paritarias entre los cónyuges en las tareas de cuidado y en las responsabilidades familiares, para asegurar la igualdad real de oportunidades y evitar que esas tareas y responsabilidades constituyan un factor discriminatorio en perjuicio de las mujeres en diferentes ámbitos, en especial en la esfera laboral".

59 Procuración General de la Nación (2017) CNT 57589/2012/1/RH1 “Puig, Fernando Rodolfo c/ Minera Santa Cruz SA s/ Despido" 
En cuanto a la interpretación de las leyes laborales, señaló que

el referido marco constitucional, vinculado con el derecho a formar una familia y con el deber estatal de promover la distribución equitativa de las responsabilidades familiares, es el que impone interpretar las normas laborales aludidas en el sentido más amplio posible, de modo de asegurar a todos los trabajadores la protección especial de la vida familiar otorgada por la ley laboral, sin distinción de género. Esta protección amplia es además la vía adecuada para asegurar la igualdad real de oportunidades y de trato en el empleo de las mujeres -artículo 75 , inciso 23 Constitución Nacional-, históricamente segregadas en las relaciones laborales a causa de la asunción de responsabilidades familiares y tareas de cuidado ${ }^{60}$.

Por otra parte, el art. 179 es discriminatorio respecto de niños y niñas que dependen para acceder al espacio de cuidado en el lugar de trabajo de que su padre o madre trabaje en un establecimiento con el número mínimo de trabajadoras que se establezca, lo que viola su derecho a la igualdad de oportunidades.

Debemos señalar al respecto que el Comité de Expertos en Aplicación de Convenios y Recomendaciones de la OIT Referidas al Convenio sobre los trabajadores con responsabilidades familiares (C 156 OIT), para el caso de la norma chilena sobre esta materia que fija como número mínimo de trabajadoras el de veinte, ha expresado que "estas disposiciones podrían causar el efecto no deseado, de que las empresas otorgaran el empleo a hombres y no a mujeres a fin de ahorrar los costos de las guarderías en el caso de llegar a 20 mujeres empleadas." ${ }^{\text {. }}$.

\footnotetext{
60 Procuración General de la Nación (2017) CNT 57589/2012/1/RH1 “Puig, Fernando Rodolfo c/ Minera Santa Cruz SA s/ Despido"

61 Solicitud directa (CEACR) - Adopción: 2000, Publicación: 89a reunión CIT (2001) www.ilo. org/dyn/normlex/es/f?p=1000:13100:0::NO:13100:P13100_COMMENT_ID,P11110_COUNTRY_ID, P11110_COUNTRY_NAME,P11110_COMMENT_YEAR:2190788,102588,Chile,2000
} 
Nuestro país también ha sido objeto de numerosas observaciones sobre estas cuestiones por parte de organismos internacionales que controlan el cumplimiento de los tratados.

Entre ellas, en 2011 el Comité DESC de Naciones Unidas, que monitorea el cumplimiento del Pacto Internacional de Derechos Económicos, Sociales y Culturales, señaló que "alienta al Estado parte a considerar las opciones legales, la creación de capacidad y los servicios que permitan a mujeres y hombres conciliar sus obligaciones profesionales con sus obligaciones familiares" ${ }^{\prime \prime 2}$.

Luego, en 2016 el Comité de Derechos Humanos expresó que "El Estado parte debe redoblar sus esfuerzos para eliminar los estereotipos de género sobre el papel y las responsabilidades de los hombres y de las mujeres en la familia y en la sociedad" ${ }^{\prime 3}$. También en 2016 el Comité de CEDAW recomendó al Estado promover "el reparto equitativo de las tareas domésticas y familiares entre hombres y mujeres, prestando servicios de guardería suficientes y adecuados" y adoptar "medidas legislativas y no legislativas para facilitar la conciliación de las responsabilidades laborales y de cuidados de personas" ${ }^{164}$.

En base a todo lo expuesto, concluimos entonces en la inconstitucionalidad del art. 179 en cuanto la obligación de establecer los espacios de cuidado infantil en el establecimiento

\footnotetext{
62 Comité de Derechos Económicos, Sociales y Culturales (2011) “Examen de los informes presentados por los Estados partes en virtud de los artículos 16 y 17 del Pacto. Observaciones finales del Comité de Derechos Económicos, Sociales y Culturales - Argentina". http:// docstore.ohchr.org/SelfServices/FilesHandler.ashxenc=4sIO60SmIBEDzFEovLCuWOfp9m5Po YHYLH3qkguOgxyvfzMwXx3FNnTOtMrqX5VDqszNG803d1cW7EzjSFRKtY\%2\%2b46Lt0A0eC WNvdcVgy1PxWJ01yt0Nvo8If3GxqM6W Acceso en 26/08/2018

63 Comité de Derechos Humanos (2016) "Examen de los informes presentados por los Estados partes en virtud del artículo 40 del Pacto Observaciones finales sobre el quinto informe periódico de Argentina" http://acnudh.org/comite-de-derechos-humanos-ccpr-argentina-2013/

64 “Comité para la Eliminación de la Discriminación contra la Mujer (2016) “Observaciones finales al séptimo informe periódico de Argentina" disponible en http://cdh.defensoria.org. ar/wp-content/uploads/sites/10/2018/03/informe-CEDAW.pdf
} 
de trabajo se encuentra condicionada al número de "trabajadoras". Ello con independencia de la eventual reglamentación que se dicte, ya que el decreto no podría modificar este aspecto del artículo y por tanto estos conflictos no podrían ser resueltos en esa instancia, subsistiendo su inconstitucionalidad.

Coincidimos plenamente con la opinión del Procurador General en "Etcheverry" referida a la lesividad a derechos fundamentales de la norma en su redacción actual y con los argumentos brindados al respecto. Sin perjuicio de ello, advertimos que la definición de esta cuestión por vía de la reglamentación podría dar lugar a planteos impugnatorios de la misma.

Aún en el supuesto en que la reglamentación estableciera el número de trabajadoras en el mínimo posible, es decir dos, el empleador podría contratar menos mujeres que esa cantidad para no encontrarse comprendido dentro de la obligación, sin importar el número de trabajadores bajo su dependencia, lo que refuerza las inequidades señaladas.

\section{Conclusiones}

A lo largo del trabajo hemos analizado la relación entre el trabajo de las mujeres y el cuidado, con particular énfasis en el de la primera infancia, dejando expuesta la injusta organización social del cuidado. La sobrecarga de las mujeres en estas tareas incide negativamente en su inserción en el mercado de trabajo, y es una de las causas de las "brechas de género" desarrolladas. Esta situación es una expresión del sistema androcéntrico, patriarcal y capitalista en que vivimos, generando pobreza y desigualdad de género, que a su vez se relacionan y retroalimentan.

La regulación del cuidado infantil debe garantizar a todas las personas que trabajan los derechos a cuidar y a poder desarrollar sus carreras laborales en condiciones de igualdad, y a la vez garantizar el derecho de niños y niñas a ser cuidados por quien/es sean sus responsable/s. Ello requiere generar distintos 
mecanismos para lograr un abordaje integral. Asimismo, supone resolver la situación de quienes trabajan informalmente y considerar la de monotributistas y autónomos.

El Estado debe asumir un rol fundamental en este tema como regulador, garante y prestador, a fin de modificar la injusta organización social del cuidado actual. Garantizar que el cuidado infantil sea universal promueve la igualdad de oportunidades entre varones y mujeres y también para niños y niñas. Ello ha sido contemplado por la normativa internacional, sin embargo, nuestra legislación laboral no ha receptado la "corresponsabilidad" estructuralmente ni en todos sus institutos.

Nuestra regulación laboral sobre esta materia no se adecua a la normativa internacional citada, ni a la Constitución Nacional, por lo que hemos concluido que la misma resulta inconstitucional. Por el contrario, reproduce inequidades de género, refuerza la feminización del cuidado y no promueve un modelo de igualdad de oportunidades. Asimismo, la norma genera interacciones entre las desigualdades de género y socioeconómicas.

Como fuera explicado, sólo una parte de quienes trabajan y tienen empleo formal se encuentran dentro de la protección de la la Ley de Contrato de Trabajo. Queda fuera de ella una gran parte de la población, que es la que se encuentra en mayores condiciones de vulnerabilidad, principalmente mujeres. Y dentro de este grupo de mujeres excluidas, un gran número se dedica precisamente a trabajos y tareas de cuidado, ya sea como trabajadoras de casas particulares no registradas o realizando trabajo doméstico no remunerado.

En este sentido, resulta fundamental resignificar y valorar el trabajo reproductivo o doméstico, y también su redistribución.

Con respecto al artículo 179 de la Ley 20744, debemos señalar que más allá de la importancia de que la Corte Suprema confirme el fallo "Etcheverry" y el Poder Ejecutivo dicte la reglamentación para que finalmente se aplique la norma, continúa vigente que la obligación legal del empleador de disponer en su establecimiento un centro de cuidado infantil se relaciona 
con el número de trabajadoras que emplee, y no del total de personas que trabajen, lo que implica seguir reproduciendo el modelo que supone a la mujer como principal cuidadora, y no el de corresponsabilidad.

Conforme ha sido analizado, del texto de la norma surge que no se trata de una prerrogativa de la cual solo pueden hacer uso las trabajadoras, por lo que no existe obstáculo alguno para que los trabajadores también sean beneficiarios de este servicio; y que el lugar de cuidado infantil debe funcionar en el establecimiento de trabajo.

El texto actual de la norma resulta contrario a la normativa internacional reseñada y asimismo genera responsabilidad internacional del Estado argentino, ya que ésta expresamente ordena eliminar las regulaciones de carácter discriminatorio. Así lo establecen, entre otros, los artículos 2 inc. f) y 11 de la CEDAW.

Resulta necesaria y urgente la reforma de este artículo y que su reemplazo resulte operativo por sí mismo. La nueva legislación debe tener en cuenta la perspectiva de género y garantizar la equidad, considerando los principios de corresponsabilidad y de igualdad en la distribución de las tareas de cuidado. Asimismo, debe contener mecanismos y sanciones que garanticen su cumplimiento.

Por otra parte, resaltamos que la discriminación laboral es una de las formas de violencia contra las mujeres prevista expresamente en la ley 26485, que debemos prevenir y erradicar.

Garantizar más cuidados generará más igualdad. 